\title{
Green Synthesis and Characterizations of Zinc Oxide (ZnO) Nanoparticles Using Aqueous Leaf Extracts of Coffee (Coffea arabica) and Its Application in Environmental Toxicity Reduction
}

\author{
Saka Abel, ${ }^{1}$ Jule Leta Tesfaye, ${ }^{1,2}$ R. Shanmugam, ${ }^{3}$ L. Priyanka Dwarampudi, \\ Gudeta Lamessa, ${ }^{1}$ N. Nagaprasad $\mathbb{D}^{5},{ }^{5}$ Mekonen Benti, ${ }^{6}$ and Ramaswamy Krishnaraj $\mathbb{D}^{2,7}$ \\ ${ }^{1}$ Department of Physics, College of Natural and Computational Science, Dambi Dollo University, Ethiopia \\ ${ }^{2}$ Centre for Excellence-Indigenous Knowledge, Innovative Technology Transfer and Entrepreneurship, \\ Dambi Dollo University, Ethiopia \\ ${ }^{3}$ TIFAC CORE HD, Department of Pharmacognosy, JSS Academy of Higher Education and Research, JSS College of Pharmacy Ooty, \\ Tamil Nadu, India \\ ${ }^{4}$ Department of Pharmacognosy, JSS Academy of Higher Education and Research, JSS College of Pharmacy Ooty, Tamil Nadu, India \\ ${ }^{5}$ Department of Mechanical Engineering, ULTRA College of Engineering and Technology, Madurai, 625104 Tamil Nadu, India \\ ${ }^{6}$ Department of Civics and Ethical Studies, College of Social Science and Humanities, Dambi Dollo University, Ethiopia \\ ${ }^{7}$ Department of Mechanical Engineering, College of Engineering and Technology, Dambi Dollo University, Ethiopia \\ Correspondence should be addressed to Ramaswamy Krishnaraj; prof.dr.krishnaraj@dadu.edu.et
}

Received 3 July 2021; Accepted 22 July 2021; Published 18 August 2021

Academic Editor: Shanmugam Rajeshkumar

Copyright (c) 2021 Saka Abel et al. This is an open access article distributed under the Creative Commons Attribution License, which permits unrestricted use, distribution, and reproduction in any medium, provided the original work is properly cited.

\begin{abstract}
A green deposition method of zinc oxide nanoparticles using coffee leaf extraction was successfully prepared. The use of these preparation techniques is accepted by many researchers because it is nonexpensive and simple and has no environmental impact during the operation. The determination and reduction of $\mathrm{Zn}$ ions to $\mathrm{ZnO}$ NPs were characterized by using a UV-visible spectroscope. The UV-visible spectroscopy result reveals that the large band gap energy is observed in the visible region at the wavelength of $300 \mathrm{~nm}$. X-ray diffraction and SEM analysis confirm that the deposited nanoparticle is highly crystalline with (111), (222), and (100) planes and cubic shape structure. The coffee leaf extraction serves as a reducing agent for stability of the particle length, where its medicinal value outcome showed an important antibacteria of the pathogenic type which appeared on the wound. The present research deals with the green synthesis of ZnO NPs as well as its application in toxicity reduction.
\end{abstract}

\section{Introduction}

Nanotechnology is the greatest innovative research part in today's condensed material science which basically includes nanoparticles [1,2]. Nanoparticles are types of materials with a $3 \mathrm{D}$ structure, changing in magnitude from 1 to 100 nanometers. This material contains lots or 100s of atoms (molecules) that comprise different forms such as crystal structure, spherical, tubes, and amorphous [3]. Nanoparticles of metals like zinc have exceptional optical properties and electrical and magnetic material goods that make them broadly used in study and manufacturing events. Amongst the numerous behaviors of metal nanoparticles, the optical studies are more protuberant. The properties of metallic nanoparticles are because of occurrences called surfaceplasmonic resonance. The applications of metal nanoparticles includes the following: their contribution in the area of electricity as well as thermal conductors, sensors, optical and electrochemical detectors, antibacterial materials, super paramagnetic materials $[4,5]$. Mineral nanoparticles have numerous likely applications for medicinal imaging and illness cure, and they are used extensively for their diverse 
features, such as in elevation availability, good ecofriendliness, their skill in drug transmission, and governor of medication statement [6]. A massive list of properties used in the biological synthesis of metal nanoparticles exists. Plant parts, algae, fungus, bacteria, and viruses are used in the biological synthesis of nanoparticles [7]. Herbal cuttings arranged from leaf, stalks, origins, florae, and pips of plants, because of differences in composites, have unlikely possessions on the quantity and physiognomies of created nanoparticles [8, 9]. Shrubberies have a great deal of ordinary reformative and steadying materials. Plants are broadly dispersed and simply available, and they are sources of various metabolites [10]. Actual phytochemicals in the manufacture of nanoparticles contain terpenes, flavonoids, ketones, aldehydes, and carboxylic acid [11].

Additionally, reducing agents like protein, enzymes, and others have a vital role in metallic nanoparticle creation by green plants [12]. The biosynthesis techniques grow nanoparticles of good surface morphology and clear size as related to some of other physicochemical synthesization techniques [13]. The biological growth of nanoparticles depends on the existence of enzymes as well as proteins included in their depositions. Nanoscience has numerous advantages in smart medicinal providing systems. In these schemes, the medicine is endangered and preserved from the location of the entrance to the nerve [14]. The coffee plant is a climber of one to seven meters long, and it has opposite-sided leaves with bulbous moods on both edges. The parts that are commercially used are the leaves, seeds, and stems. In Oromia, Ethiopia, the leaf of coffee is not functional and no studies were conducted, and they simply drop to the ground and lead to environmental toxicity. Using this leaf regardless of its seed incorporation reduces toxicity of the water, air, and environment [15].

Deposition of green nanoparticles from the leaf extract is simpler to use. It is nontoxic, and there is no contagion exposed to the surroundings. Additionally, it is better to be substituted with other techniques of synthesization of nanoparticles. Due to the above declared evidences about the medicinal ideals of the coffee plant, the present study brought a biomimetic approach for the green synthesis of ecofriendly zinc oxide nanoparticles from coffee leaves through UV-visible spectroscopic, scanning electron microscope, X-ray diffraction characterization, and photoluminescence spectral studies.

\section{Materials and Methods}

For the synthesization of nanoparticles cut from the coffee leaf, zinc-nitrate hexahydrate and triple distilled water were arranged. All important materials are cleaned by using nitric acid and additionally by deionized water, then dehydrated by keeping it in a rotisserie before the preparation of nanoparticles. The leaves of the coffee plant were gathered from Dambi Dollo town, Ethiopia.

\section{Preparation of Extraction from Coffee Plant Leaves}

The leaves of the coffee plant (Figure 1) are collected and washed by using warm water to eradicate dirt adverts. The

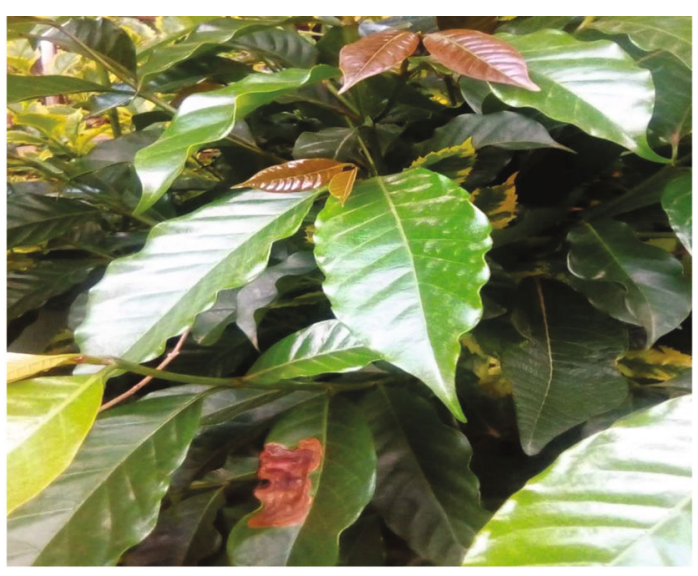

Figure 1: Coffee plant originally taken from Dambi Dollo town, Kellem Wollega, Oromia, Ethiopia.

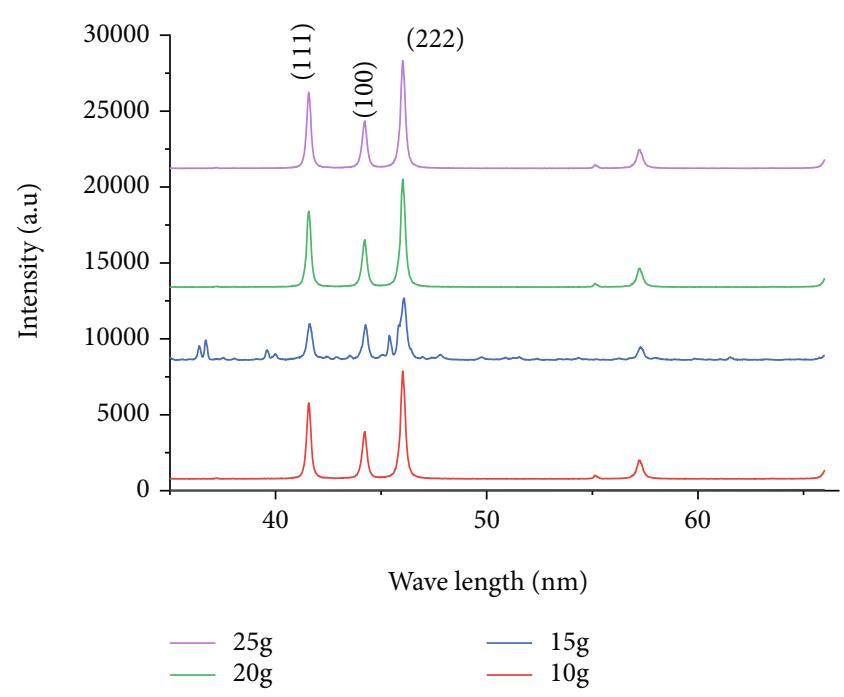

FIGURE 2: XRD patterns of $\mathrm{ZnO}$ nanoparticles from extract of coffee leaves.

leaves become dried in air after three weeks, since the season at which the present research was conducted was summer; after drying, the leaves were powdered by using a metal mortar and wood pestle till the ground very well. The extraction of coffee leaves was organized by alternatively changing the masses of prepared $\mathrm{ZnO}$ nanoparticles as $10 \mathrm{~g}, 15 \mathrm{~g}, 20 \mathrm{~g}$, and $25 \mathrm{~g}$ of powder of coffee leaves which was put into $95 \mathrm{mil}-$ liliters of distilled water at an adjusted temperature of $100^{\circ} \mathrm{C}$ for $30 \mathrm{~min}$, and the $\mathrm{pH}$ value of the solution was measured to be 5 . The solution was finally filtered and kept in a freezer at $7^{\circ} \mathrm{C}$ for further work.

\section{Deposition of ZnO Nanoparticles from Coffee Leaf Extraction}

The precursor basis for the zinc ion used in this study was zinc-nitrite hydrooxide which was taken from shops from Finfinnee, Ethiopia. The elucidation of zinc-nitrite hydrooxide was set in deionized water. For synthesization of $\mathrm{ZnO}$ 

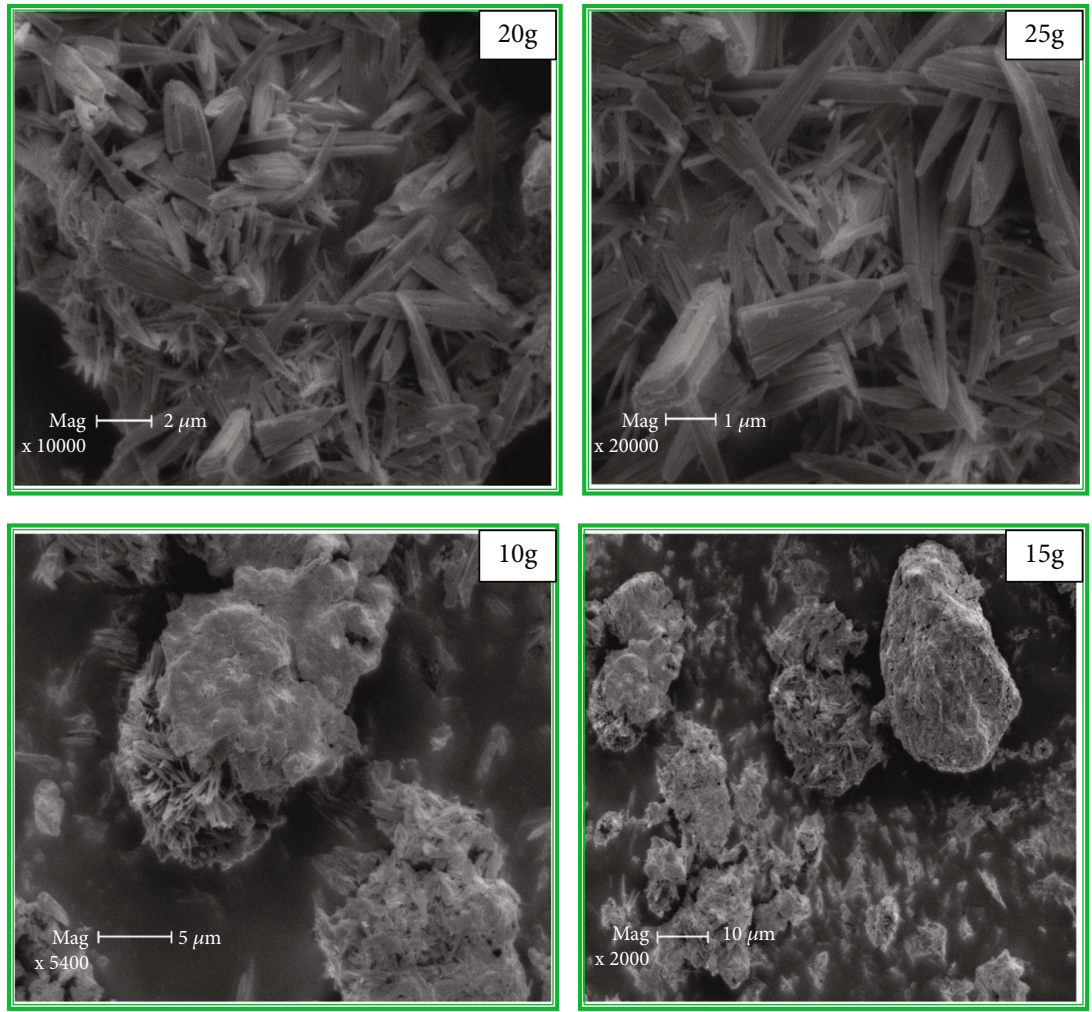

Figure 3: Scanning electron microscope analysis of $\mathrm{ZnO}$ nanoparticles at different masses of $10 \mathrm{~g}, 15 \mathrm{~g}, 20 \mathrm{~g}$, and $25 \mathrm{~g}$.

nanoparticles, the flask volume of $250 \mathrm{~mL}$ and the source of zinc $(0.1 \mathrm{M})$ was mixed with $20 \mathrm{~mL}$ of the leaf extract of the coffee leaf and stimulated on a magnetic stirrer heated at $80^{\circ} \mathrm{C}$, and the stirring was nonstop until a uniform solution was accomplished. The homogenous solution was dehydrated in a hot air oven at the temperature of $120-150^{\circ} \mathrm{C}$ for $120 \mathrm{~min}$. Currently, the color of prepared nanoparticles is yellow and is crumpled in a metallic mortar-pestle to get a green preparation of $\mathrm{ZnO}$ nanoparticles.

\section{Characterization Techniques}

XRD (Shimadzu, 50 kilovolts and 20 milliamperes with $\mathrm{Cu}-\mathrm{Ka}$ radiation with wavelength or $\lambda=1.541 \AA$ ) was cast off for crystal-structure examination. A Shimadzu ultraviolet-visible spectrophotometer was employed to assess the optical behaviors, and photoluminescence (PL) spectroscopy was also used to analyze the optical properties of the sample. Surface morphological study of the deposited nanoparticle was accompanied using scanning electron microscope (SEM) [15-17].

\section{Analysis of Crystal Structure of $\mathrm{ZnO}$ Nanoparticle Extracts of Coffee Leaves}

X-ray diffraction patterns of deposited ZnO NPs show that peaks observed agree with the ordinary data. The existing peaks of XRD (Figure 2) finely agreed with the cubic crystal structure [18]. The fitted sharp as well as peaks involving intensity in Figure 3 reveals that the nanoparticles are enor-
TABLE 1: Evaluation of calculated crystal size $D(\mathrm{~nm})$ from XRD results.

\begin{tabular}{lccc}
\hline No. & 2 theta (degree) & FWMH (radians) & $D(\mathrm{~nm})$ \\
\hline 1 & 25.61 & 0.195 & 85.51 \\
2 & 26.32 & 9.85 & 2.50 \\
3 & 32.70 & 0.255 & 56.01 \\
4 & 34.09 & 8.06 & 1.88 \\
\hline
\end{tabular}

mously crystalline. The phase can be indexed for diffractions from the (222), (111), and (100) planes.

From the XRD graphing data, the peaks produced are extensive; the portentous crystallites have sizes in the nanometer range and the diameter was calculated using Scherer's theories, given by

$$
D=\frac{K \lambda}{\beta \cos \theta},
$$

whereas $K$ is the Debye-Scherrer constant number, $\lambda$ is the $\mathrm{X}$-ray wavelength, $\beta$ is the width of the peak of half maximum, and $\theta$ is the diffraction position [19]. The calculated crystalline size of green synthesized is dignified by XRD obtained around 40 nanometers. The crystal size calculation of the $\mathrm{ZnO}$ nanoparticle is shortly discussed in Table 1. 


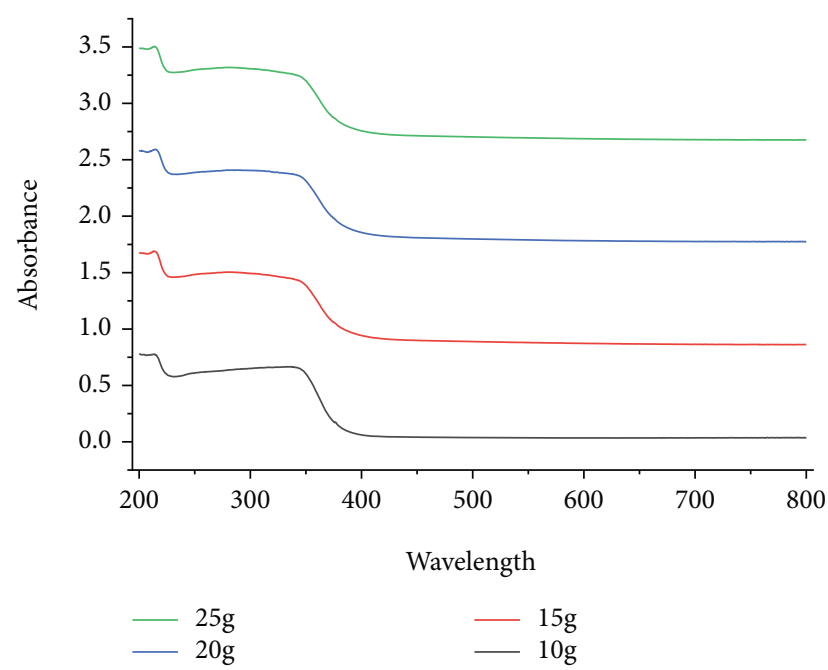

Figure 4: UV-visible of $\mathrm{ZnO}$ nanoparticles at different masses of $10 \mathrm{~g}, 15 \mathrm{~g}, 20 \mathrm{~g}$, and $25 \mathrm{~g}$.

\section{Scanning-Electron Microscope (SEM) Analysis of ZnO Nanoparticles from Coffee Leaf Extract}

Subsequently, the validation of X-ray diffraction outputs was further regulated for the surface morphology of scanningelectron-microscope characterization. The shape as well as crystal size and surface morphology of the $\mathrm{ZnO}$ nanoparticle are evidently shown by micrograph of a scanning electron microscope as shown in Figure 3.

Comprehensive structural analyses prove that the produced outputs are cubic shaped and crystal in a nice arrangement. The measured diameters were about $40 \mathrm{~nm}$. Nanoparticles at $10 \mathrm{~g}$ and $15 \mathrm{~g}$ have an astounding shape and those at $20 \mathrm{~g}$ and $25 \mathrm{~g}$ are like fixing wood. Generally, the micrograph observed has no void and cracks, and this shows high crystallinity of the sample prepared. These results agree with what has been reported [20].

\section{Ultraviolet (UV-Vis) Analysis of $\mathrm{ZnO}$ NPs from Coffee Leaf Extract}

As demonstrated in Figure 4, the immersion spectrum of the equipped $\mathrm{ZnO}$ nanoparticles with the absorption peak is nearly $360 \mathrm{~nm}$. It shows the $\mathrm{ZnO}$ nanoparticles' exposition, excitation, and absorption (at $360 \mathrm{~nm}$ ) because of their big excitation binding energy at room temperature. The bands of zinc colloids were alleged at $360 \mathrm{~nm}$, which reveals that the zinc ion is capably minimized by coffee leaf extraction. The appearance of the blue-shifted absorption spectrum with deference to the large value $(300 \mathrm{~nm})$ of the $\mathrm{ZnO}$ nanoparticles appropriate for the wavelength of the 300-nanometer fascination peak, due to the quantum captivity effect, which is in good agreement with the previously reported [21-23].

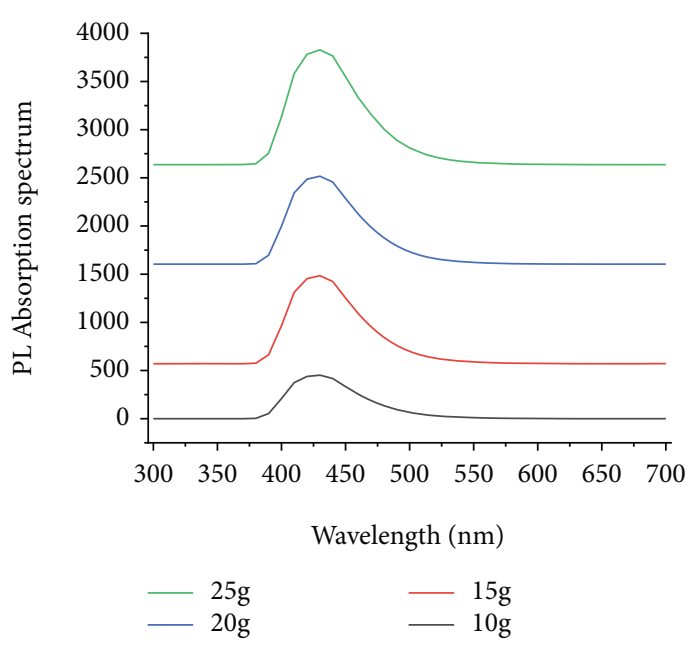

Figure 5: Photoluminescence spectra of $\mathrm{ZnO}$ NPs with different masses of $10 \mathrm{~g}, 15 \mathrm{~g}, 20 \mathrm{~g}$, and $25 \mathrm{~g}$.

\section{Photoluminescence (PL) Spectral Analysis}

Photoluminescent nanoparticles progress as dissimilarity or theranostic proxy assurances to make conceivable the inspection of a precise biological phenomenon as well as the action of diseases with a maximum degree of discernment. Consequently, novel nanoscale ingredients on condition of having higher finding limits, multimodal imaging modalities, and improved therapeutic effects are currently under study. This characterization technique is also used to analyze the optical emission properties of $\mathrm{ZnO}$ nanoparticles [24-32].

The PL behaviors of the deposited nanoparticles are shown in Figure 4. Based on the peaks of photoluminescence radiations, it was perceived that with addition of volume of nanoparticles of $\mathrm{ZnO} \mathrm{NPs}$, the intensity of photoluminescence peak was increasing with large area to volume rate for small-sized crystalline. This could be predictable to number of icons in the nanoparticles superficial fustily increases as crystal sizes decreases. Hence, the nanoparticles with a small crystal size can characterize the highest luminescence intensity related to the biggest crystal solid [24-29]. This could be predictable to number of ions in the nanoparticles superficial fustily increases as crystal size declines. Moreover, as shown in Figure 5, the trailer recombination rate rises as the size declines due to the increase in intersection between the electron (e-) and hole $(\mathrm{P}+)$ with increasing volume of $\mathrm{ZnO}$ NPs of $10 \mathrm{~g}, 15 \mathrm{~g}$, $20 \mathrm{~g}$, and $25 \mathrm{~g}$ [33-47].

\section{Conclusion}

The green synthesis method of ZnO NPs was efficaciously formed using the leaf of the coffee plant. The biological synthesis method used is meek, easily biodegradable, and prepared in a short period of time. The existing yellow color shows the deposition of zinc oxide nanoparticles, which has 
supplementarily long established the minimization of zinc ions in zinc oxide nanoparticles by using UV-Vis spectroscopy. The ultraviolet spectroscopic absorption records the highest peak at $300 \mathrm{~nm}$, and PL analysis also confirmed this statement. X-ray diffraction and scanning electron microscope analysis show that the particle-prepared behavior was polycrystalline with no void cubic-shaped zinc oxide nanoparticles. Finally, very high-quality green-synthesized $\mathrm{ZnO}$ nanoparticles are obtained for medical application and toxicity reduction.

\section{Data Availability}

The data used to support the findings of this study are included within the article.

\section{Disclosure}

This study was performed as a part of the employment of the authors.

\section{Conflicts of Interest}

The authors declare that there are no conflicts of interest.

\section{References}

[1] S. Faisal, H. Jan, S. Shah et al., "Green synthesis of zinc oxide $(\mathrm{ZnO})$ nanoparticles using aqueous fruit extracts of Myristica fragrans: their characterizations and biological and environmental applications," ACS Omega, vol. 6, no. 14, pp. 97099722, 2021.

[2] A. Jayachandran, A. TR, and A. S. Nair, "Green synthesis and characterization of zinc oxide nanoparticles using Cayratia pedata leaf extract," Biochemistry and Biophysics Reports, vol. 26, article 100995, 2021.

[3] R. A. Gonçalves, R. P. Toledo, N. Joshi, and O. M. Berengue, "Green synthesis and applications of $\mathrm{ZnO}$ and $\mathrm{TiO}_{2}$ nanostructures," Molecules, vol. 26, no. 8, p. 2236, 2021.

[4] M. C. Patino-Portela, P. A. Arciniegas-Grijalba, L. P. Mosquera-Sanchez et al., "Effect of method of synthesis on antifungal ability of $\mathrm{ZnO}$ nanoparticles: chemical route vs green route," Advances in nano research, vol. 10, no. 2, pp. 191-210, 2021.

[5] S. Awan, K. Shahzadi, S. Javad, A. Tariq, A. Ahmad, and S. Ilyas, "A preliminary study of influence of zinc oxide nanoparticles on growth parameters of Brassica oleracea var italic," Journal of the Saudi Society of Agricultural Sciences, vol. 20, no. 1, pp. 18-24, 2021.

[6] M. S. E. D. Salem, A. Y. Mahfouz, and R. M. Fathy, "The antibacterial and antihemolytic activities assessment of zinc oxide nanoparticles synthesized using plant extracts and gamma irradiation against the uro-pathogenic multidrug resistant Proteus vulgaris," Biometals, vol. 34, no. 1, pp. 175-196, 2021.

[7] R. Hamouda and M. Elshamy, "Using biosynthesized zinc oxide nanoparticles to alleviate the toxicity on banana parasitic-nematode," Research, vol. 67, article 271, 2021.

[8] M. Raafat, A. S. A. el-Sayed, and M. T. el-Sayed, "Biosynthesis and anti-mycotoxigenic activity of Zingiber officinale roscoederived metal nanoparticles," Molecules, vol. 26, no. 8, p. 2290, 2021.
[9] A. Naseer, A. Ali, S. Ali et al., "Biogenic and eco-benign synthesis of platinum nanoparticles (Pt NPs) using plants aqueous extracts and biological derivatives: environmental, biological and catalytic applications," Journal of Materials Research and Technology, vol. 9, no. 4, pp. 9093-9107, 2020.

[10] M. Asemani and N. Anarjan, "Green synthesis of copper oxide nanoparticles using Juglans regia leaf extract and assessment of their physico-chemical and biological properties," Green Processing and Synthesis, vol. 8, no. 1, pp. 557-567, 2019.

[11] S. Ahmad, S. Munir, N. Zeb et al., "Green nanotechnology: a review on green synthesis of silver nanoparticles - an ecofriendly approach," International Journal of Nanomedicine, vol. 14, pp. 5087-5107, 2019.

[12] R. Abbasian and H. Jafarizadeh-Malmiri, "Green approach in gold, silver and selenium nanoparticles using coffee bean extract," Open Agriculture, vol. 5, no. 1, pp. 761-767, 2020.

[13] S. Sarli, M. R. Kalani, and A. Moradi, "A Potent and Safer Anticancer and Antibacterial Taxus-Based Green Synthesized Silver Nanoparticle," International Journal of Nanomedicine, vol. 15, pp. 3791-3801, 2020.

[14] M. S. Jameel, A. A. Aziz, and M. A. Dheyab, "Green synthesis: proposed mechanism and factors influencing the synthesis of platinum nanoparticles," Green Processing and Synthesis, vol. 9, no. 1, pp. 386-398, 2020.

[15] A. Banerjee, A. Sarkar, K. Acharya, and N. Chakraborty, "Nanotechnology: an emerging hope in crop improvement," Letters in Applied NanoBioScience, vol. 10, no. 4, pp. 27842803, 2021.

[16] S. Painuli, P. Semwal, A. Bachheti, R. K. Bachheti, and A. Husen, "Nanomaterials from non-wood forest products and their applications," Nanomaterials for Agriculture and Forestry Applications, vol. 33, pp. 15-40, 2020.

[17] J. Devasia, B. Muniswamy, and M. K. Mishra, "Investigation of $\mathrm{ZnO}$ nanoparticles on in vitro cultures of coffee (Coffea Arabica L.)," International Journal of Nanoscience and Nanotechnology, vol. 16, no. 4, pp. 271-277, 2020.

[18] W. J. Keijok, R. H. A. Pereira, L. A. C. Alvarez et al., "Controlled biosynthesis of gold nanoparticles with Coffea arabica using factorial design," Scientific Reports, vol. 9, no. 1, article 52496, pp. 16019-16110, 2019.

[19] L. Rossi, L. N. Fedenia, H. Sharifan, X. Ma, and L. Lombardini, "Effects of foliar application of zinc sulfate and zinc nanoparticles in coffee (Coffea arabica L.) plants," Plant Physiology and Biochemistry, vol. 135, pp. 160-166, 2019.

[20] J. I. García-López, G. Niño-Medina, E. Olivares-Sáenz et al., "Foliar application of zinc oxide nanoparticles and zinc sulfate boosts the content of bioactive compounds in habanero peppers," Plants, vol. 8, no. 8, p. 254, 2019.

[21] L. P. Mosquera-Sánchez, P. A. Arciniegas-Grijalba, M. C. Patiño-Portela, B. E. Guerra-Sierra, J. E. Muñoz-Florez, and J. E. Rodríguez-Páez, "Antifungal effect of zinc oxide nanoparticles (ZnO-NPs) on Colletotrichum sp., causal agent of anthracnose in coffee crops," Biocatalysis and Agricultural Biotechnology, vol. 25, article 101579, 2020.

[22] A. Bakir, S. Hamimed, A. Landoulsi, and A. Chatti, "Biogenic Zinc Oxide Nano-Structures Differentiation under Musical Sounds," 2021.

[23] S. Nurman, R. Yulia, I. Irmayanti, E. Noor, and T. Candra Sunarti, "Optimizing anti-inflammatory activities of Arabica coffee ground (Coffea arabica L.) nanoparticle Gel," Journal of Natural Pharmaceutical Products, vol. 16, no. 2, pp. 1-9, 2021. 
[24] R. Pavelkova, P. Matouskova, J. Hoova, J. Porizka, and I. Marova, "Preparation and characterisation of organic UV filters based on combined $\mathrm{PHB} /$ liposomes with natural phenolic compounds," Journal of Biotechnology, vol. 324, article 100021, 2020.

[25] T. Desalegn, C. R. Ravikumar, and H. C. A. Murthy, "Ecofriendly synthesis of silver nanostructures using medicinal plant Vernonia amygdalina Del. leaf extract for multifunctional applications," Applied Nanoscience, vol. 11, no. 2, pp. 535-551, 2021.

[26] C. Song, M. Huang, J. C. White et al., "Metabolic profile and physiological response of cucumber foliar exposed to engineered $\mathrm{MoS}_{2}$ and $\mathrm{TiO}_{2}$ nanoparticles," NanoImpact, vol. 20, article 100271, 2020.

[27] M. Baghaienezhad, M. Boroghani, and R. Anabestani, "Silver nanoparticles synthesis by coffee residues extract and their antibacterial activity," Nanomedicine Research Journal, vol. 5, pp. 29-34, 2020.

[28] M. M. Cohen, "Tulsi - Ocimum sanctum: a herb for all reasons," Journal of Ayurveda and integrative medicine, vol. 5, no. 4, article 146554, pp. 251-259, 2014.

[29] S. Abel, J. Leta Tesfaye, R. Kiran et al., "Studying the effect of metallic precursor concentration on the structural, optical, and morphological properties of zinc sulfide thin films in photovoltaic cell applications," Advances in Materials Science and Engineering, vol. 2021, Article ID 7443664, 6 pages, 2021.

[30] L. Tesfaye, B. Bekele, A. Saka, N. Nagaprasad, and K. Sivaramasundaram, "Investigating spectroscopic and structural properties of $\mathrm{Cr}$ doped $\mathrm{TiO}_{2} \mathrm{NPs}$ synthesized through sol gel deposition technique," Tierarztliche Prax., vol. 41, pp. 860872, 2021.

[31] L. Tesfaye Jule, K. Ramaswamy, N. Nagaprasad, V. Shanmugam, and V. Vignesh, "Design and analysis of serial drilled hole in composite material," Materials Today: Proceedings, vol. 45, pp. 5759-5763, 2021.

[32] L. Tesfaye Jule, K. Ramaswamy, B. Bekele, A. Saka, and N. Nagaprasad, "Experimental investigation on the impacts of annealing temperatures on titanium dioxide nanoparticles structure, size and optical properties synthesized through solgel methods," Materials Today: Proceedings, vol. 45, pp. 5752-5758, 2021.

[33] T. Amuthan, N. Nagaprasad, R. Krishnaraj, V. Narasimharaj, B. Stalin, and V. Vignesh, "Experimental study of mechanical properties of AA6061 and AA7075 alloy joints using friction stir welding," Materials Today: Proceedings, vol. 46, 2021.

[34] E. K. Subramaniam, M. Sakthivel, K. Kanthavel, R. Krishnaraj, and R. Palani, "Overall resource effectiveness, cycle time reduction \& capacity improvements," International Journal of Scientific and Engineering Research, vol. 2, no. 8, pp. 1-5, 2011.

[35] P. Dharmalingam, K. Kanthavel, R. Sathiyamoorthy, M. Sakthivel, R. Krishnaraj, and C. Elango, "Optimization of cellular layout under dynamic demand environment by simulated annealing," International Journal of Scientific and Engineering Research, vol. 3, no. 10, pp. 1-7, 2012.

[36] V. M. M. Thilak, R. Krishnaraj, M. Sakthivel, K. Kanthavel, M. Marudachalam, and R. Palani, "Transient thermal and structural analysis of the rotor disc of disc brake," International Journal of Scientific and Engineering Research., vol. 2, no. 8, pp. 2-5, 2011.

[37] S. Varatharajan, R. Krishnaraj, M. Sakthivel, K. Kanthavel, and R. Palani, "Design and analysis of single disc machine top and bottom cover," International Journal of Scientific and Engineering Research, vol. 2, no. 8, pp. 1-6, 2011.

[38] C. M. Balamurugan, R. Krishnaraj, M. Sakthivel, K. Kanthavel, D. Marudachalam, and R. Palani, "Computer aided modeling and optimization of crankshaft," International Journal of Scientific and Engineering Research, vol. 2, no. 8, pp. 2-7, 2011.

[39] M. Vyshakh, R. K. Raj, A. P. Sayooj, and M. Afzal, "Experimental investigation on aluminium gravity die casting," International Journal of Applied Environmental Sciences, vol. 9, no. 2, pp. 213-222, 2014.

[40] M. Deepu, R. K. Raj, D. Karthik, and N. M. Binoj, "Cycle time optimization of rubber floor mat die," International Journal of Applied Environmental Sciences., vol. 9, no. 2, pp. 229-237, 2014.

[41] V. S. Arun, R. Krishnaraj, M. N. Rohit, and V. Mohan, "Optimising rejection rate of laser diamond sawing using Taguchi method," International Journal of Applied Environmental Sciences, vol. 9, no. 2, pp. 223-228, 2014.

[42] M. Dakshinamoorthy, M. B. K. Moorthy, M. Sakthivel, R. Krishnaraj, and N. Rajkumar, "Investigation on the effect of thermo physical properties on heat and mass transfer review," International Journal of Applied Environmental Sciences, vol. 9, no. 4, pp. 1893-1900, 2014.

[43] C. N. A. Kumar, R. Krishnaraj, M. Sakthivel, and M. Arularasu, "Implementation of safety education program for material handling equipment in construction sites and its effectiveness analysis using T-test," International Journal of Applied Environmental Sciences, vol. 8, no. 15, pp. 1961-1969, 2013.

[44] L. T. Jule, R. Krishnaraj, N. Nagaprasad, B. Stalin, V. Vignesh, and T. Amuthan, "Evaluate the structural and thermal analysis of solid and cross drilled rotor by using finite element analysis," Materials Today: Proceedings, vol. 47, 2021.

[45] N. Nagaraj, S. Balasubramaniam, V. Venkataraman, R. Manickam, R. Nagarajan, and I. Sikiru Oluwarotimi, "Effect of cellulosic filler loading on mechanical and thermal properties of date palm seed/vinyl ester composites," International Journal of Biological Macromolecules, vol. 147, pp. 53-66, 2020.

[46] N. Nagaprasad, B. Stalin, V. Vignesh, M. Ravichandran, N. Rajini, and O. Ismail, "Applicability of cellulosic-based Polyalthia longigolia seed filler reinforced vinyl ester biocomposites on tribological performance," Polymer Composites, vol. 42, no. 2, pp. 791-804, 2021.

[47] B. Kassa, J. Leta Tesfaye, B. Bulcha et al., "Effect of Manganese Ions on Spectroscopic and Insulating Properties of Aluminophosphate Glasses," Advances in Materials Science and Engineering, vol. 2021, Article ID 6253069, 11 pages, 2021. 